\title{
DE LOS TAMBOS INCAS A LAS TAMBARRÍAS COLONIALES: ECONOMÍA COLONIAL, LEGISLACIÓN DE TAMBOS Y ACTIVIDADES «LICENCIOSAS» DE LAS MUJERES INDÍGENAS
}

\author{
Sofía Chacaltana Cortez ${ }^{2}$
}

\begin{abstract}
Resumen
Cuando llegaron los españoles a los Andes, alabaron los caminos y tambos incaicos que encontraron mientras avanzaban a través del agreste territorio andino. A pesar de que durante y luego de la conquista española los tambos sufrieron un gran deterioro, fueron una de las pocas instituciones que continuaron funcionando durante la época colonial. Los hispanos se dieron cuenta rápidamente de que estos edificios eran de gran necesidad para su economia basada en el comercio y en la explotación minera, sistema que para funcionar requería del transporte de gente, objetos y animales. Por ello, pese a que los tambos estaban inmersos en un sistema económico mercantilista colonial, los españoles dispusieron de una serie de cédulas que promovían la reinstitucionalización de los tambos como en la época de "Guaynacapac». En este artículo, me sirvo de datos históricos que refieren a la legalización del funcionamiento de los tambos y a las prácticas ocurridas en ellos para observar las múltiples fricciones entre los hispanos e indigenas. Además, llamo la atención sobre un aspecto en particular: la obsesión española sobre el cuerpo de la mujer indigena, que devela la ideología de poder colonial. Al final del artículo, discuto la importancia de la arqueología para contribuir con un mejor entendimiento sobre la transformación de esta institución desde la época prehispánica hasta la colonial.
\end{abstract}

Palabras clave: tambos, economía colonial, mujeres indigenas, mita de tambo, legislación de tambo, identidades coloniales

Abstract

FROM INKA TAMBOS TO COLONIAL TAMBARRÍAS: LAW, ECONOMY AND THE "LICENTIOUS" ACTIVITIES OF INDIGENOUS WOMEN

Historical accounts of the Iberian incursion into the Andes indicate that Spaniards were amazed by the sophisticated roads and waystations (tambos) they encountered across Andean territory. During and after the Iberian conquest, indigenous and Spanish armies constantly burned tambos for strategic reasons, in order to slow the movement of enemy troops. Despite this practice, tambos were one of the few institutions that continued during the colonial period. The Spanish rapidly recognized that tambos were beneficial for their economy, specifically markets and mining exploitation that required the movement of people, things, and animals across the Andean region. Consequently, during the early colonial period, Iberians dictated laws promoting the smooth functioning of tambos as a way of regulating the practices occurring in them; transforming tambos into a new colonial institution. In this article, I call attention to the transformation of tambos from a pre-Hispanic to a colonial institution as well as the colonial desire to control indigenous behavior in the new Andean society. I specially focus on the colonial fixation over the bodies of indigenous women, illustrating some aspects of the ideology of power exerted over indigenous communities. Finally, I discuss the importance of archaeology to better understand the transformation of tambos from the pre-Hispanic to the colonial period.

Keywords: tambos, waystations, colonial economy, indigenous women, mita of tambo, tambo legislation, colonial identities

a Universidad Antonio Ruiz de Montoya y Field Museum of Natural History

Correo electrónico: sofichacaltana@hotmail.com/schacaltana@fieldmuseum.org 
"Yten por que los yndios suelen tener en los tanbos yndias que biven mal husando mal de sus cuerpos con los caminantes y con otros so color que es para pagar el tributo y porque esto es cosa de mal exenplo se manda que de aqui a delante cese tan mal huso y desto tengan particular cuydado el corregidor del repartimiento y los caciques y alcaldes de los indios [...]»

(Rostworowski 1975: 151).

\section{Introducción}

Los tambos incas fueron edificios de tamaño pequeño a mediano sistemáticamente construidos cada 15 a 20 kilómetros de distancia a lo largo de los principales caminos del Qhapaq Nan, que unificó de forma ideológica y espacial el territorio del Tawantinsuyo, el más grande imperio de la América precolombina. Irónicamente, a pesar de que los tambos fueron instituciones con una alta presencia en los Andes, es una de las menos entendidas. Actualmente, los investigadores están de acuerdo en que uno de los principales roles de estas instituciones fue proveer comida y alojamiento a los viajantes (desde los ejércitos imperiales a los chaskis) (Hyslop 1984, 1990), y que las comunidades indígenas ubicadas en sus alrededores suplieron a los sistemas de almacenamiento (qolqas) y trabajaron como personal atendiendo a los viajantes (tampucamayoc) bajo el sistema de mita (tributo laboral temporal). En otras palabras, al igual que otros requerimientos del imperio inca, los tambos funcionaron bajo el sistema de reciprocidad y redistribución característico de la economía inca (y prehispánica), y estuvieron sustentados y administrados por oficiales imperiales inmersos en un jerárquico sistema burocrático inca (Murra 1980: 105; Chacaltana 2010: 41-45).

Asimismo, debido a las investigaciones sistemáticas llevadas a cabo por John Hyslop (1984) en diferentes tramos del Qhapaq Nan, se entendió que estas instituciones estuvieron compuestas por estructuras específicas que cumplían diferentes funciones, como qolqas o almacenes; las kallankas o patios abiertos, que fueron recintos rectangulares de tamaño variable en donde se llevaron a cabo diversos tipos de actividades; y las kanchas, que fueron lugares abiertos delimitados por kallankas u otras estructuras (Hyslop 1990). Hyslop (1984), además, menciona que, aparte de las qolqas, las kanchas fueron las formas arquitectónicas que definían a los tambos, ya que permitían albergar a grandes cantidades de gentes. A pesar de identificar a las estructuras y las funciones que componen los tambos, este investigador también sugirió que, debido a la variabilidad del medio ambiente, geografía y la organización del tránsito del imperio, los tambos pueden tener variantes en sus componentes. Esto responde a que, aparte de proveer comida y alojamiento a los viajantes imperiales y a los militares, los tambos también pudieron tener funciones adicionales, como edificios donde se llevaban a cabo ceremonias (espacios ceremoniales y/o económicos), donde se realizaban funciones político-administrativas, funciones artesanales (talleres de producción), entre otros (ver Helsley 1980; Bárcena 1988; Morris 1992; Tschauner 2001; INC 2004; Flores y Revilla 2006; Chacaltana 2010, 2011) (Fig. 1).

Este reconocimiento sobre la variabilidad de los roles adicionales que cumplían los tambos, así como la variación en el tamaño de las estructuras básicas y su disposición, a su vez, ocasionó algunas confusiones respecto a la forma y función de los mismos. En otras palabras, la identificación de los roles específicos y adicionales que podían tener los tambos se confundió con la variabilidad arquitectónica de sus componentes. A pesar de que los investigadores reconocieran el número mínimo de los elementos arquitectónicos que componen los tambos, esta confusión entre la forma (expresión material) y la función (rol) generó que los investigadores identificaran a algunos sitios incas como los sitios administrativos y/o ciudades coloniales, iguales que a los tambos.

Esta confusión en la identificación de estos edificios en el registro arqueológico se ha visto intensificada por la transformación de los tambos durante y luego de la llegada de los espańoles al territorio andino. Cuando los españoles comenzaron su expansión en los Andes, los tambos fueron 


\section{kallanka \\ Kallanka}

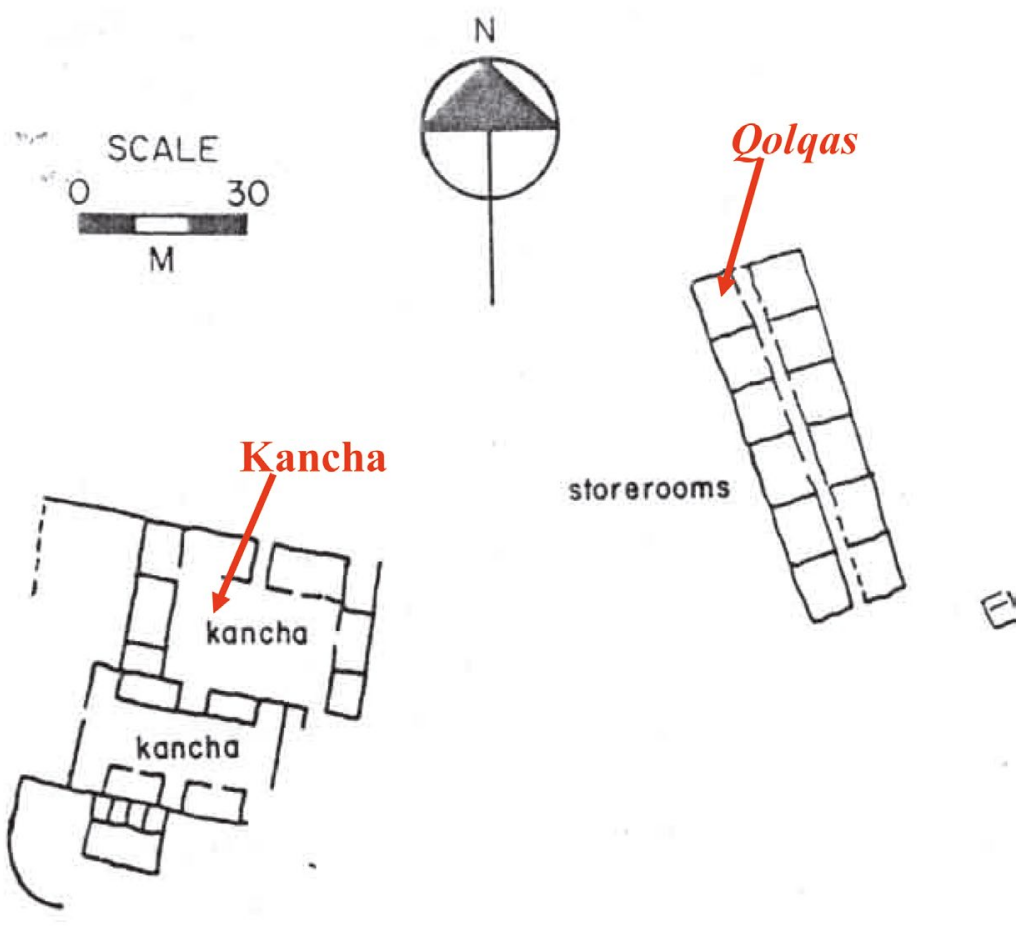

Figura 1. Plano que muestra las diferentes unidades arquitectónicas que componen un tambo Inca (Dibujo tomado de John Hyslop 1984: 31).

unas de las primeras instituciones que colapsaron. Al parecer, esto ocurrió por dos razones principales: la primera fue que tanto los espańoles como el ejército indígena destruyeron y vandalizaron los tambos que encontraron en su camino a manera de detener o impedir el movimiento de las tropas adversarias (Xeres 1872 [1534]; Pizarro 1969 [1571]: 229-230). La segunda razón es que los tambos eran administrados por los llactacamayocs o los tucuyricoc (Julien 2006; Matienzo 1910 [1567]: 3), quienes fueron oficiales imperiales que estaban encargados de la administración de los tambos y de velar por los intereses estatales en las provincias ${ }^{1}$. Estos oficiales habrían regresado a su lugar de origen después de que colapsó el Imperio inca. Por ello, hubo una fuerte intención colonial de rehabilitar a los tambos según tiempos prehispánicos.

Finalmente, se sugiere que esta confusión sobre la función y forma de los tambos incas —y, por consecuencia, coloniales - aumentó debido a las descripciones realizadas por algunos cronistas, como Juan Diez de Betanzos (2004 [1557]: 154) y Guamán Poma de Ayala. Betanzos, quien escribió alrededor del año 1570, mencionó que los tambos fueron lugares donde el ejército inca podía acomodarse y descansar, como Huánuco Pampa y Pumpu, y que estos edificios estaban «el vuelo de halcón" (Xuco Huamán) separados uno del otro. Por otro lado, Guamán Poma de Ayala (1944 [1614]) describió y enumeró una lista de los tambos ubicados a lo largo del Qhapaq Nan del Tawantinsuyo. Asimismo, escribió décadas más tarde que Betanzos sugirió cinco categorías distintas de tambos. La primera categoría corresponde a "Ciudad o mezón real», que refiere a las grandes ciudades como Cajamarca y Lima. La segunda categoría es la «Ciudad y mezón real», que 
alude a ciudades más pequeñas, como Nazca y Cañete, mientras que la tercera fue «Ciudades con tambos» para referirse a los sitios incas administrativos, como Huánuco Viejo y Jauja. La cuarta corresponde a los «Tambos con ciudades», pequeñas estructuras con personal, como el Tambo de Taparacu y el Tambo de Tunsukacha, ambos en Huánuco. Finalmente, la quinta y última categoría fue los «Tambillos», que no tenían personal ni recaudo («sin recaudo ni pulpería, ni gente»), pero sí tenían espacios abiertos donde se podían ubicar los animales (Poma de Ayala 1944 [1614]: 1072-1082).

Ante estas descripciones, existen dos aspectos que deben ser considerados. Uno es que la descripción y la clasificación de los tambos realizadas por Guamán Poma en su Nueva Crónica y Buen Gobierno (1614), la cual es utilizada por muchos arqueólogos en la actualidad, ya en 1614 refleja las transformaciones ocurridas desde la época prehispánica a la colonial. El segundo aspecto es que las prácticas económicas y sociales ocurridas durante los primeros años de instalada la sociedad colonial y las diversas políticas coloniales a las que fueron sometidas los tambos como instituciones, las que se mencionaran más adelante ${ }^{2}$, rápidamente transformaron los tambos incas en instituciones coloniales. Motivos por los cuales tanto las descripciones de Betanzos como las de Guamán Poma de Ayala utilizan los mezones o tambos como categorías utilizadas para identificar a grandes ciudades como Lima, y sitios administrativos incas como Pumpu y Huanuco Pampa, así como edificios que actualmente son reconocidos como tambos, como lo son Tunsukancha y Taparacu; así, confunden la institución de los tambos y sus roles con las descripciones físicas de los mismos.

En un trabajo anterior, he sugerido que las estructuras y espacios presentes en los tambos, así como su numerosa presencia en los Andes, no solo indican las actividades llevadas a cabo en ellos, sino que también el tipo de interacción establecida entre el imperio y las comunidades locales (ver Chacaltana 2010: 146-156). Esto es importante tomarlo en cuenta, porque permite observar a los tambos como instituciones que promovían una interacción fomentada y auspiciada por el imperio a nivel local. Para el caso de los Andes, las relaciones entre los imperios, los líderes locales y las poblaciones estuvieron articuladas en complejas interacciones de reciprocidad y redistribución que eran constantemente reafirmadas (Morris y Covey 2003). En este sentido, los tambos articulaban a las distintas y diversas comunidades de los Andes con el imperio, y llegaban a ser una institución exitosa y eficaz, puesto que se utilizó a una escala no vista anteriormente en la América precolombina.

En la actualidad, nuestro entendimiento de los tambos está principalmente basado en las descripciones coloniales y en pocos estudios arqueológicos. Existen algunas ideas sobre los posibles roles de los tambos durante el período inca, pero aún no comprendemos enteramente a estas instituciones. Por ello, se sugieren las siguientes interrogantes: ¿De qué manera se articularon los tambos con las comunidades locales?, ¿qué tipos de roles jugaron en las diferentes regiones de los Andes?, ¿en qué extensión fueron estos roles determinados por el imperio o por las necesidades de las comunidades locales?

\section{Economía colonial}

La economía colonial era de naturaleza extractiva. Desde épocas coloniales tempranas, aparecieron haciendas de producción agrícola, como azucareras, algodoneras con obrajes para la producción textil, molinos en los que se procesaban granos — como el trigo—; y viñedos para la producción del aguardiente, vino y brandy. Asimismo, surgieron las ciudades mineras de Porco, Huancavelica y Potosí (Lockhart 1994). Esta economía requirió la movilización de las poblaciones indígenas para que cumplieran la mita de trabajo y transportaran productos (Glave 1989; Cańedo-Arguelles 2005). De igual modo, la presencia de las minas provocó la movilización y la aparición de negocios relacionados con el transporte de licores a lo largo de los Andes surperuanos, como Arequipa, Moquegua, y de los valles sureños hacia el Cuzco, Potosí y La Plata (Glave 1989). Por otro lado, la economía colonial también giraba alrededor de la encomienda colonial. La encomienda fue instaurada como parte del sistema legal colonial, a través del cual la Corona española encomen- 
daba un grupo de nativos a los conquistadores en recompensa por su servicio. De esta forma, los encomenderos eran los responsables de adoctrinar a los indios en las prácticas de la religión católica, así como sus protectores legales. En retorno, los indios estaban obligados a pagar tributos a la Corona y al encomendero, servir en la versión colonial de la mita, y dar servicio personal a las autoridades coloniales (Lockhart 1994). De este modo, la encomienda pasó a ser una institución que afectó gravemente la salud, y el nivel de vida de las mujeres y los hombres de los Andes.

\subsection{Economía marginal de la mujer indígena}

La construcción legal e ideológica colonial sobre la participación de las mujeres en la economía fue muy restrictiva, pero, en la práctica, tuvo otra historia, la cual se puede apreciar en los tambos. La encomienda imponía el tributo obligatorio o la mita colonial a los varones indígenas y no a las mujeres; no obstante, en la práctica, las mujeres indígenas también participaron dentro de esta economía, aunque de manera marginal (ver Viera Powers 2005: 142). Por ejemplo, las mujeres viajaban acompañando a sus maridos mientras estos cumplían su mita de trabajo minera a distintas ciudades. En varias ocasiones, los mitayos viajaban con sus familias, pero, cuando llegaban a las ciudades mineras, los hombres ingresaban a trabajar por casi toda la semana en el socavón, así que las mujeres entraban a formar parte de la economía urbana como sirvientas de las casas de españoles, vendedoras de comida en los mercados; incluso, trabajaban en las minas haciendo trabajos menores, aunque algunas participaron como mano de obra junto a los varones (ver Silverblatt 1987). Por otro lado, las mujeres que se quedaban en los pueblos también ingresaron a formar parte de la economía colonial apoyando a sus comunidades (maridos y familiares) a alcanzar los altos y duros tributos de la encomienda.

De esta forma, la vida de las mujeres indígenas estuvo llena de múltiples tareas que iban desde la crianza de los hijos, labores agrícolas y las domésticas, hasta la producción textil en obrajes que aparecieron en muchos lugares de la Colonia que estaba sustentado en la mita femenina (ver Silverblatt 1987: cap. VII). En consecuencia, y de manera "no lícita», las mujeres indígenas formaron parte activa e importante de la economía colonial (Socolow 2000) al estar a cargo de las tareas que tradicionalmente fueron masculinas mientras sus parejas fueron a realizar la mita indígena a las minas, $y$, en muchos casos, pasaron a representar ejes de intercambio entre los indígenas, los criollos y los españoles (Burkett 1990 [1978]; Espinoza Soriano 1997: 172-176).

En este sentido, es importante notar que las mujeres indígenas (esclavas negras y mestizas), quienes estaban en el último peldaño de la jerarquía social colonial, entraron a formar parte de la economía colonial de manera marginal cumpliendo trabajos que eran considerados como degradantes. Esto responde a que ideológicamente, durante la época colonial temprana, los tipos de ocupaciones estaban relacionadas con las diferentes castas y razas existentes; en ese marco, la calidad moral de las personas estaba articulada a las mismas (Burkett 1990 [1978]; Viera Powers 2005). Ante los ojos coloniales, las mujeres indígenas eran consideradas como carentes de honor, orgullo y honra, y, por lo tanto, sin "nada que perder» (Mannarelli 1990, 1993, 1998). Entre las ocupaciones más comunes, estaba la preparación de alimentos, tanto dentro de las casas de los españoles como en casas de curacas que tenían capacidades económicas. Muchas mujeres fueron las encargadas de vender sus productos en los mercados y se las permitía dentro de los tambos para que trabajaran como amasadoras de pan (para indígenas, o, incluso, para esclavos negros y españoles). En estos, como consecuencia de la falta de moral que se les atribuía, participaban en actividades licenciosas o no morales, las que abordaremos más adelante.

\section{Legislación de tambos y conflictos}

En esta parte, se discuten las instrucciones de tambos dadas durante la época colonial temprana en algunas zonas de los Andes. En especial, nos enfocamos en las normativas provistas que sugieren 
sobre las prácticas que estaban ocurriendo en los tambos. De esta forma, también vemos que este proceso de transformación tuvo como consecuencia la construcción tipológica de tambos dada por Guamán Poma de Ayala en 1614. Así, en primer lugar, se analizan las ordenanzas de Cristóbal Vaca de Castro realizadas en 1543 y, luego, las Ordenanzas de Tambo de 1567 por el doctor Gregorio Gonzales de Cuenca en Huamachuco, basadas en la visita que realizó al norte del Perú. Asimismo, planteo algunos comentarios sobre la información de tambos en la visita a los Lupacas de Chucuito de Diez de San Miguel durante 1567. Luego, se desarrollan algunas ideas sobre las disposiciones realizadas por Francisco de Toledo con respecto a los tambos para observar la transformación de estas instituciones, en las que se dispone fueran llamadas ventas o mesones, y no tambos. Finalmente, de manera breve, se comentan dos pleitos de tambos ocurridos a finales del siglo XVI hasta principios del siglo XVII en dos zonas del Perú: uno ocurrido en el valle de Sihuas en Arequipa y el otro, en el altiplano boliviano.

En general, desde los primeros años de la conquista ibérica, se puede observar que existió un intento colonial de legislar a los tambos a manera de ventas, similares a las que existían en la península Ibérica de la época, y que funcionaban como empresas privadas (ver Glave 1989). En los Andes, esta legislación estuvo, a su vez, influenciada por la idea colonial de que los tambos continúen desempeñándose como en la época de «Guaynacapac» (durante las primeras décadas de la Colonia). Al respecto, varios investigadores han reconocido que los españoles asumieron que sus instituciones hispanas tuvieron categorías equivalentes en el mundo andino (Zárate 1995 [1555]: VII; Salomon 1998), pero se deja de lado que las mismas categorías ibéricas sufrieron transformaciones y, de cierta manera, estuvieron sumergidas en un proceso de indianización (ver Estenssoro 2010), proceso que trataremos de revelar en los análisis de tambos ofrecidos a continuación.

En 1543, el licenciado Cristóbal Vaca de Castro escribió las primeras y más famosas litigaciones sobre los tambos: «Ordenanzas de Tambos. Distancia de unos a otros, modo de cargar los indios y obligaciones de las justicias respectivas hechas en la ciudad del Cuzco» ${ }^{3}$. Uno de los principales propósitos de las litigaciones fue la reinstitucionalización del sistema de tambos como en la época de «Guaina Capac» a consecuencia de los constantes maltratos sufridos por los indígenas. Al respecto, el oidor escribe lo siguiente:

Primeramente por que la causa principal por que reciben los Indios daño muerte y diminución el cargarlos es por no estar los Tambos antiguos del tiempo de Guaynacaba y sus antepasados poblados como estaban quando estos Reynos se ganaron y redusieron al servicio y obediencia de S.M. siendo en sus tiempos los Indios cargados se mandaban o daban a otros o havia bastimientos o lo necesario en depósitos para los dichos Indios sin que lo llevasen a sobre las dichas cargas, y por no estar al presente assi los dichos Tambos les falta lo susodicho o an de llevar o llevan su comida sobre las dichas cargas y pasan muchas jornadas con las cargas hasta parte poblada (Vaca de Castro 1908 [1543]: 429).

De esta forma, el oidor Vaca de Castro hizo una lista de varios "tambos incas» que debían ser reconstruidos para funcionar como sistema de alojamiento en las rutas principales. Asimismo, él enumeró una lista de las comunidades indígenas que tenían que servir en cada uno de los tambos enunciados. Esta reconstrucción, además, sugería que los tambos estén a cargo de una autoridad española (alguacil de tambo) designada por los encomenderos, quien debía residir en este edificio y estar a cargo de un grupo de tambos (de tres a cuatro tambos) (ibid.: 457-459). Se resalta que Vaca de Castro realiza una lista de tambos, pero no una jerarquía de tambos similar a la que hizo Guamán Poma de Ayala. En esta ordenanza, también se indica que los caminantes no deben detenerse por más de una noche en un tambo y que no deben recibir comida por más de dos veces, a no ser que se queden en los tambos a causa de enfermedad (ibid.: 476). Por otro lado, se menciona que no se dé carne «ni a los yanaconas ni a los indios ni Indias' que los españoles llevaren consigo [en sus viajes]» (ibid.: 453), pero que sí se les debía de proveer de agua, leña y yerba de indios (para esta fecha, el recaudo de tambos que eran los productos básicos, como leña, agua y yerba, aún no era cobrado). Otro aspecto mencionado por estas ordenanzas es que se regulaba las libras (el peso) que los indígenas podían llevar como carga (máximo de 30 libras), y se sugiere que los españoles que 
residan en los tambos tengan peso o romana (ibid.: 469) para que los indios no puedan caminar con pesos mayores ${ }^{4}$. Es importante notar que, en estas ordenanzas, no existen disposiciones sobre el arancel (impuesto) ni se enuncian los tipos de productos que podían ser vendidos en los tambos. Al parecer, en esta época, se inicia el proceso de regulación de la transformación de tambos a ventas.

Por otro lado, mientras la economía colonial iba consolidándose en los Andes, los primeros aranceles (impuestos) para tambos fueron establecidos alrededor de 1549 y 1550 (Glave 1989), cuando Pedro de la Gasca fue presidente del virreinato del Perú (Lockhart 1994). Estas disposiciones fueron dadas en Lima y estuvieron basadas en los aranceles que debían aplicarse en los tambos de todo el virreinato, pero que eran manejados a manera local. Así, en 1550, se dieron los aranceles dispuestos en Jauja: «Mandamiento para que los españoles y caciques de los tambos principales del camino de Jauja tengan los víveres necesarios para el servicio de quienes lo solicitan», emitido por el corregidor Rodrigo Cantos de Andrada (Glave 1989: 127)5. Los aranceles y disposiciones sobre tambos permitían que estos tengan productos necesarios para el servicio de los transeúntes que lo soliciten; en estos, indígenas así como los españoles podían vender algunos productos. La diferencia radicaba en que se indicaba que lo que ganaban los indios debía ser incorporado en la caja de la comunidad y no ser una ganancia individual. De esta forma, en los aranceles mencionados se enunciaban productos ibéricos como locales. Por ejemplo, en el emitido en Jauja, se dispone vender los siguientes productos: pan, maíz, papas, vino de Castilla y de Huamanga, chicha, gallinas, capones, perdices y carneros de Castilla, aceitunas, higos, pasas, y pescado; en los aranceles de Quito, se nombran los siguientes productos: maíz, papa, pan amasado, biscocho, gallinas y pollos, conejos, venado y cerdo, huevos, sal, quínoa, alpargatas, cabuya, jáquima, un cabestro y una suelta, una olla de manteca de azumbre, una petaca encorada, un cántaro de chica (¿chicha?). En estos documentos, notamos la clara transformación de los tambos hacia una idea de venta «ibérica»; asimismo, se evidencia que la lista de ingredientes sugiere diversos tipos de dietas, tanto ibéricas como indígenas. Hubo, además, productos que eran parecidos a los que eran almacenados en las qolqas de los tambos prehispánicos, como maíz, papa, quínoa, alpargatas y herramientas o utensilios para cocinar ( $c f$. Morris 1967, 1986).

Algunos años después, se promulgaron dos ordenanzas dadas por oidor Gregorio Gonzales de Cuenca: la primera fue dirigida al cacique de Jayanca (sierra de Lambayeque); y la segunda, realizada para la región de Huamachuco (sierra de La Libertad). Estas ordenanzas trataban de organizar y erradicar algunas costumbres indígenas (ver Rostworowski 1975). La primera — de Jayanca-, dictada en 1566 por Cuenca, contiene algunos aspectos importantes sobre la organización del funcionamiento de los tambos en esta comunidad. La segunda es la llamada «Ordenanzas para el servicio de los tambos del Repartimiento de Huamachuco", por Cuenca en 1567 a solicitud de los indios de esta región (Rostworowski 1987-1989).

En las ordenanzas de Cuenca para el cacique de Jayanca, dadas en 1566, vemos que se designa que los alcaldes de indios (de elección anual y escogidos por un alcalde español) fueran los encargados del funcionamiento de tambos. Estos debían supervisar que los tambos estuviesen abastecidos de víveres, que tengan arancel de tambo, mitayos para servir a los transeúntes, y tenían que asegurarse de que los caminos estén reparados (Rostworowski 1975: 132). Por otro lado, en las mismas ordenanzas, se designa que los caciques y principales (que no eran necesariamente los encargados de tambos) estén directamente a cargo de "probeher y señalar los yndios que an e servir en el tambo y en reparo de puentes e caminos y calcadas y los que an de servir en la villa de Miraflores» (ibid.: $139)^{6}$. Estas ordenanzas también sugieren que se prohíba que los caciques anden en hamacas aunque sí podían hacerlo a caballo (ibid::145) ${ }^{7}$, y que la mita de tambos la realicen los indios «conocidos y fieles», puesto que habían algunos indios que robaban a los caminantes o a las cargas (ibid.: 152).

Por otro lado, las ordenanzas de tambo dadas en Huamachuco son interesantes por varias razones. Una de ellas es que estas se hicieron a requerimiento de los mismos indígenas con el objetivo de disminuir los trabajos de la mita que realizaban en los nueve tambos de la zona. La otra razón es que se observa una relación entre algunos tambos con ayllus y/o comunidades locales que podría estar reflejando las relaciones de reciprocidad desarrolladas, y aún existentes, entre ayllus y 
el ya desaparecido Imperio inca. Al respecto, en Huamachuco, hubo varias quejas planteadas por los indígenas; entre las principales, resaltan las siguientes:

- Los indios yungas de tierras calientes se enfermaban, porque iban a dar su mita a tambos ubicados en la Xallca (zona de la selva alta), que era tierra fría. Los cambios drásticos de temperatura, sugerían, producían enfermedades (Rostworowski 1987-1989: 23).

- Otra queja fue que los indios «sufrían por el largo viaje» que debían hacer a pueblos que estaban muy lejos del tambo donde se les requería para hacer la mita ${ }^{8}$. Esta última queja por parte de los indios sobre la mita de tambo, es muy recurrente.

Así, estos nueve tambos mencionados eran atendidos por seis guarangas ${ }^{9}$, dos de las cuales eran de mitimaes (uno yungas y el otro serrano), y se observan los siguientes aspectos importantes en relación con su organización. Dos tambos nombrados como «Tambos Reales» fueron Huamachuco y Yangon (ibid.). Estos «Tambos Reales» tenían 30 mitayos trabajando en cada uno de ellos. Los otros siete tambos - Cucho, Uruchal, Congayo, Andamarca, Yanabamba, Collanbaya y Uruchal de Lima - solo contaban con 10 mitayos cada uno. Esta diferencia de trabajo requerido en los tambos sugiere que la demanda del número de mitayos en un tambo dependía del uso del mismo dentro de la economía colonial (número de personas que utilizaban los tambos).

De esta forma, realizando una lectura detenida de esta ordenanza, se hacen evidentes varios aspectos. El primero es que los pobladores de una guaranga ${ }^{10}$ servían en varios tambos, pero, al parecer, algunas guarangas daban un mayor número de mitayos a tambos específicos. Por ejemplo, la guaranga de Andamarca mandaba 10 indios mitayos al tambo de Andamarca, y era la única guaranga que servía en ese tambo, aunque también mandaba cinco mitayos al tambo de Uruchal de Lima. Lo mismo ocurría con la guaranga mencionada como chaupi yunga, que era la única guaranga que daba mitayos al tambo de Collanbay, y era este el único tambo que se encargaba esta guaranga. Finalmente, otro caso similar es la guaranga de Llucho, que daba cinco indios al tambo de Llucho (o estuvo nombrado inicialmente y, si lo incluimos, serían 10 tambos en vez de nueve), y esta misma guaranga otorgaba nueve indios al «Tambo Real» de Guamachuco. Así, el tambo de Llucho solo era atendido por los pobladores del pueblo de Yanabanba y de Agomarca, que pertenecían a la guaranga de Llucho. Por otro lado, las otras dos guarangas restantes — como la de Llampa - daban mitayos a varios tambos ${ }^{11}$. De este modo, notamos que algunas guarangas eran encargadas de tambos específicos.

Cabe anotar que los tambos nombrados en esta visita no se encontraban en una sola ruta, sino que estuvieron dispersos en el repartimiento. Es importante tomar en cuenta esto, puesto que se tiende a asumir que los pobladores de una comunidad específica mitaban en el tambo más cercano ${ }^{12}$. No obstante, al parecer, un tambo podía recibir mita de pobladores de guaranga que contaban con pueblos lejanos y cercanos a este, pese a que existían otros pueblos de otras guarangas más cercanos que no necesariamente mitaban en el mismo tambo. Otro punto a tomar en cuenta es que esta ordenanza hace una diferenciación entre "tambos reales» y otros tipos de tambos. Se sugiere que la diferenciación planteada en la presente ordenanza estuvo más relacionada con la transformación de los tambos a manera de ventas (por la existencia de aranceles de tambos, así como la mención de tambo reales a dos sitios que no son tambos) que a los diversos tipos de tambos existentes durante la época inca.

Ahora pasamos a analizar la visita de Chucuito, realizada el mismo año de la Ordenanza de Huamachuco. Esta fue dictada en 1567 por Garci Diez de San Miguel en los Andes surcentrales. En general, la ruta o el camino que pasaba por Chucuito y los pueblos lupacas localizados en el Urcosuyo — es decir, la zona oeste del lago Titicaca — fue muy transitada. Durante la época colonial temprana, por estos caminos reales, circulaba todo tipo de gente, como mitayos que iban a cumplir su mita minera a Potosí, así como los trajines compuestos por indígenas y españoles (muchos de ellos adinerados) que trasladaban mercadería (vino, aguardiente, textiles, entre otros) a Cuzco, u otros sitios como Arequipa, Potosí y Moquegua (Glave 1989). 
Esta visita tuvo la intención de supervisar el tributo dado por los indígenas lupacas a la Corona española. La visita involucraba una lista de preguntas realizadas por el visitador a los indígenas dentro de un ambiente teatralizado, en el que los españoles (el visitador y su séquito jurídico como los ayudantes escribanos e intérpretes) representaban a la autoridad legal y los indígenas desempeñaban un rol a partir del cual, a su vez, se creaba su identidad «indio» (Guevara-Gil y Salomon 2004). Estos interrogatorios implicaban realizar preguntas ya programadas a los caciques (dos caciques principales hanan y hurin), a los diferentes jefes locales (de las siete cabeceras de cada parcialidad hanan y hurin), y a varios españoles (vecinos) que residían en la región. Entre las preguntas realizadas a los indígenas, hubo interrogantes sobre el servicio de tambos que habían otorgado durante el tiempo inca, así como el que daban en la época colonial. Sobre la base de las respuestas dadas, al final del documento de la visita, se incluyen las disposiciones (o acuerdos) tomadas respecto al uso de los tambos y la mita indígena en Chucuito.

En respuesta a las interrogantes de la visita, los caciques mencionaron que, durante el tiempo de los incas, ellos recibían directamente productos del Estado para sustentar a los tambos. En otras palabras, los productos utilizados para dar de comer a los transeúntes de la provincia (ejércitos y viajantes oficiales) eran provistos por el Estado (Diez de San Miguel 1964 [1567]: 22, 34). Por otro lado, en las respuestas brindadas por los jefes de los pueblos de las parcialidades hanan y hurin que fueron interrogados respecto a la mita colonial, se aprecia que la mita de tambo se otorgaba en la ciudad de Chucuito, lugar donde se quedaba la mayoría de personas que transitaba por esta región. De este modo, se sugieren dos conclusiones importantes: la primera es que en Chucuito vivían españoles que utilizaban a indígenas para manejar sus propios tambos como negocios o ventas ${ }^{13}$. La segunda es que los indígenas continuaban dando mita en los tambos que tradicionalmente habían servido. El servicio de tambos en esta región lo llevaban a cabo ambas parcialidades (hanan y hurin) que tenían responsabilidades de ayudarse entre ellos y al Estado para servir en ciertos tambos de la región (ibid:: 96). Asimismo, al igual que la Ordenanza de Huamachuco, se distingue que durante la Colonia se daba un mayor número de indígenas para la mita de tambo a una ciudad ocupada por españoles que a los mismos tambos.

En la visita de Chucuito, podemos notar que los indígenas recibían muchos abusos en los tambos donde trabajaban (en los que recibían muy poca paga o ninguna). Por ello, en la misma visita, se dispone que exista un jornal de trabajo indígena, que los indios solo puedan llevar carga de un tambo a otro tambo (y no caminar largas distancias) y que no lleven demasiado peso sobre sus hombros. Además, ya en esta visita se nota que los tambos funcionaban como ventas y lugares donde se vendían «libremente» productos (incluso, se señala que algunos indígenas vendían maíz de la costa), hasta hubo españoles que vendieron productos a los viajeros y a los mismos indígenas (Diez de San Miguel 1964 [1567]: 25-26).

\subsection{Legislaciones de Toledo}

Se revisa las disposiciones de tambos planteadas durante el período de Francisco de Toledo, virrey del Perú desde 1569 hasta 1581. Toledo fue considerado como un gran legislador, efectivo por haber luchado contra la idolatría de indios en los Andes y por ser un persuasivo inquisidor de las costumbres indígenas. Su gobierno estuvo caracterizado por emitir disposiciones que limitaron las capacidades indígenas en el ámbito ritual, político y económico (Julien 2007). Así sus instrucciones tomaron un mayor control de los tributos dados por los indígenas; estas fueron favorables para la Corona y perjudiciales para los indígenas.

En general, Toledo prohibió o limitó la autoridad de los caciques (o alcaldes de indios) (Glave 1989) con el fin de crear una mayor distancia entre las actividades administrativas, y de control de los corregidores de indios (españoles) y los alcaldes de indios (indígenas). Entre sus prohibiciones dictaminadas, se planteó que los alcaldes de indios ya no pudieran designar a los indios para hacer la mita de tambo y caminos. Esta designación debía de ser decisión de un consejo de caciques; luego, pasar por los alcaldes y regidores para ser, finalmente, emitida bajo ordenanza por él 
mismo (Lohmann Villena 1989 [1575-1580]). La justificación a esta nueva disposición fue evitar que los caciques utilizaran la mano de obra indígena para su propio beneficio. A pesar de ello, Toledo designó que los alcaldes indígenas sean los responsables de cuidar y visitar los tambos de su pueblo, y percatarse de que estén correctamente provistos. Toledo también señaló que, para evitar hurtos en los tambos, los indios que trabajasen en ellos debían ser fieles y conocidos, y mayores de 17 años (ibid.: 246).

Del mismo modo, el virrey Toledo sugirió que sean los corregidores ${ }^{14}$ los responsables directos de los tambos (ibid.: 242-243). A partir de las ordenanzas establecidas por Toledo, los corregidores tenían la obligación de mantener a los tambos poblados con indígenas de pueblos cercanos y «no como de costumbre» (es decir, con indígenas de poblaciones lejanas). Hay que tomar en cuenta que estas disposiciones se realizaron luego de que se dieran las órdenes para las reducciones de indios, momento en el que empezó a cambiar la configuración del paisaje social en los Andes.

Entre las Ordenanzas de Toledo, hay dos conocidas como «las Ordenanzas de Tambos»: una es para Huamanga en 1571, y la otra es la "Ordenanza para las ventas y mesones de Charcas» en 1574 (Lohman Villena 1986 [1570-1574]). En estas ordenanzas, Toledo sugiere que se cambie el nombre de tambos a mesones o ventas, debido a que bajo el nombre de tambo se habían cometido muchos abusos contra los naturales. El virrey escribe:

Por cuanto en la visita general que por mi persona hago en estos reinos, he estendido las vajaciones,
daños y agravios que los naturales reciben en el servicio de los tambos y ventas, así por estar ocupados
de ordinario en el dicho servicio y obligados a él tanto número de indios, como en hacerlos venir de
muy lejos de diferentes [...] he dado la orden, que más ha parecido que convenía, quitando este nombre
de tambos; y ordenando que S.M. quiere y manda que se hagan ventas y mesones lo más semejante que
sea posible a los que hay en los reinos de Espańa y que los indios no sean cargados por el camino [...].
(Levillier 1925: vol. VII, 273-280).

En conclusión, en estas ordenanzas, se puede notar un doble discurso, y un conflicto entre las legislaciones dadas y la ideología imperante sobre el funcionamiento de los tambos durante la época prehispánica. El legislador escribe: «[...] que fuesen a servir a los dichos tambos con cierto número de indios y mantenimientos, quedando en su fuerza y vigor aquella obligación para que si en algún tiempo se les mandare tornar a servir los dichos tambos conforme a ella y a su costumbre sean obligados a venir, se ha mandado y manda que cese aquella manera de servicio [...]» (Lohman Villlena 1986 [1570-1574]: 74). Así, a pesar de que Francisco de Toledo quiso cambiar el nombre de los tambos por el de ventas, en 1575, la infraestructura de caminos fue incorporada al Estado y se requirió funcionaran basándose en la mita de tambo provista por los indígenas de los pueblos más cercanos (lo cual se sabía que no era costumbre local). De esta manera, los tambos, así como los caminos, establecieron un servicio mercantil a cambio de un salario estipulado que se llevó a cabo fuera de la encomienda.

Todas estas nuevas estipulaciones causaron conflictos entre los mismos indígenas, debido a que - como lo mencionamos anteriormente - hubo comunidades o ayllus que estaban a cargo de tambos específicos (a veces, responsabilidad compartida), y otras comunidades que, a partir de la ausencia del Estado inca, ya no querían continuar con esa responsabilidad, como lo veremos a continuación en un pleito ocurrido en la sierra sur.

\subsection{Disputa de tambos}

Bajo esta coyuntura, los tambos en ocasiones se transformaron en un problema para los hispanos. Por un lado, estas instituciones fueron necesarias para continuar con la economía colonial, como el transporte de licor y metal. Por otro lado, como protectores de los indios, los españoles se dieron cuenta de que los tambos representaban una desventaja moral y física para las poblaciones andinas.

En la literatura, existen muchos ejemplos sobre disputas de tambos. En este artículo, de manera breve, mencionaré solo dos. La primera es una disputa protagonizada por los caciques de Sihuas y 
de Cabana por el número de mitayos enviados al tambo de Sihuas, ubicado en el valle de Sihuas, a 1700 metros sobre el nivel del mar (Barriga 1939 [1534-1558]: Tomo I, 384-386). La comunidad de Sihuas estaba ubicada cerca al tambo; en cambio, la población Cabana estaba localizada en el mismo valle, pero a 4000 metros sobre el nivel del mar. El otro caso fue una disputa ocurrida en territorio Pacajes, región en la zona sur del lago Titicaca (Glave 1989: 137-143; Mumford 2007). Esta disputa fue protagonizada entre los curacas de la mitad Omasuyo y los curacas de la mitad Urcusuyo del territorio Pacajes, la primera comunidad ubicada al este, y la segunda, hacia el oeste de la misma región.

El tambo de Sihuas ubicado en el valle medio del mismo nombre fue un punto de parada importante a lo largo del camino, que conectaba la ciudad costera de Camaná con las ciudades serranas de Arequipa y Cuzco. Este tambo fue utilizado por muchos mercaderes para el transporte de camarones, pescado y vino de la costa hacia la sierra (Cardona 2008). Esta disputa comenzó en 1557, cuando don Pedro, cacique de Sihuas, reclamó sobre el servicio de mita de los indios de Cabana. Don Pedro argumentó que, desde que los indios cabanas interrumpieron su ayuda en el tambo de Sihuas, los indios de su comunidad habían dejado de trabajar en sus tierras agrícolas, porque estaban muy ocupados en tratar de servir a los viajantes que paraban en este tambo. Asimismo, el cacique también argumentó que era un pedido legítimo, puesto que muchos años antes el corregidor La Gasca instruyó a los indios cabana que sirvieran en el tambo de Sihuas. En respuesta, el cacique de Cabana afirmó que ya no mandaba a sus indios al tambo de Sihuas, porque la gente de su comunidad sufría demasiado cuando viajaban a Sihuas. Este cacique explicaba que, debido a que los indios cabanas eran de tierras frías, caían enfermos cuando viajaban a tierras cálidas (como es el caso del clima de la zona en la que estaba el tambo de Sihuas). Asimismo, también señaló que, incluso, algunos españoles hacían que los indios cabanas viajaran hasta Camaná, donde caían aún más enfermos estando en tierras aún más cálidas. Finalmente, el líder cabana arguyó que el tambo de Sihuas era una tienda privada que pertenecía al encomendero Antonio Gomez Buytron, quien lo había vendido a otro español llamado Juanes Navarro, y que el último había puesto en este tambo a un «negro» para vender leña, paja y comida a los viajantes. De esta forma, algunos indios y españoles que fueron entrevistados en esta disputa indicaron que este «negro» tomaba ventaja y abusaba de los indios, porque les hacía trabajar mucho en el servicio de tambo. También, indicaban que tomaba ventaja de las esposas de los indios haciendo que limpiaran los tambos, y «si estas mujeres eran atractivas y jóvenzuelas, él se las ofrecía a los viajantes» (Barriga 1939 [1543-1558]: Tomo I, 384-386). De esta manera, al final de la disputa, los indígenas de Cabana fueron liberados de servir en el tambo de Sihuas. Uno de los puntos que fortaleció el argumento presentado fue el hecho de que el tambo era un negocio privado y que, bajo estas circunstancias, los indios no tenían que dar mita de trabajo (ibid.: 384-386).

El otro caso revisado es el iniciado por los caciques de Pacajes Omasuyo. Estos caciques solicitaban ayuda en el servicio de tambo a los caciques de Pacajes Urcosuyo. Esta disputa legal duró mucho tiempo, ya que empezó en 1562 y continuó hasta el siglo VII. La provincia de Pacajes estuvo dividida en dos mitades, una conocida como Pacajes Omasuyo, y la otra como Pacajes Urcosuyo. La segunda tenía mayor jerarquía y se encontraba cerca del camino que atravesaba Pacajes Omasuyo. Este camino fue bastante transitado por gente y animales, debido a que conectaba Potosí con el Cuzco. En la disputa, los líderes Omasuyo argumentaban que ellos tenían el derecho legítimo de reclamar ayuda a los Urcosuyo, puesto que estos eran «más ricos y tenían más animales» y que, de esa manera, había ocurrió durante el tiempo de «Guaina Capac». A pesar de ello, luego de ańos de disputa, los Pacajes Urcosuyo ganaron el juicio contra los Pacajes Omasuyo, con lo cual consiguieron que los indios de la parte Omasuyo dieran mita en los tambos de la mitad Urcosuyo.

En conclusión, en estos dos ejemplos de disputas de tambos, podemos observar las maneras en que estas instituciones se fueron transformando bajo las leyes del mercado. Asimismo, vemos las ocasiones en que los indígenas emplearon el marco legal para sus propios beneficios manipulando 
ciertos conceptos "prehispánicos» que tenían resonancia en la legislación colonial. Finalmente, durante la época colonial temprana, los tambos adquirieron sus propias particularidades como consecuencia de las políticas coloniales ejecutadas, las cuales veremos a continuación.

\section{De los tambos inca a las tambarrías coloniales: transformación del espacio}

En la sección anterior, hemos observado algunos aspectos que caracterizaron a la transformación de los tambos en ventas o mesones. A continuación, nos enfocaremos en algunas consecuencias causadas por esta transformación. De manera breve, llamaré la atención sobre las «actividades licenciosas» que se denunciaron ocurrían en estos espacios y que involucraban a las mujeres indígenas. Este tema sugiere una investigación más profunda, puesto que aborda aspectos importantes en relación con la construcción del cuerpo de la mujer indígena y la manipulación política de la sexualidad en contextos de colonización (Ballantyne y Burton 2005).

En general, durante el siglo XVII, en algunas regiones de los Andes, los tambos fueron llamados «tambarrías» y fueron sinónimos de burdeles (Botmiliau 1947 [1848]; Espinoza 2005: 195; Lopez-Baralt 2003). Estos edificios representaron instituciones coloniales con características específicas. En primer lugar, muchos de estos edificios se encontraban fuera de las ciudades ibéricas e indígenas; eran lugares donde paraban y pasaban un gran número de pasajeros inmersos dentro de una economía mercantil. En segundo lugar, en las ordenanzas, se indica que los indígenas y españoles tenían que descansar (dormir y comer) en espacios distintos e, incluso, tener dietas disímiles de acuerdo a su «raza». En tercer y último lugar, se sugiere que, estando los tambos coloniales fuera de las ciudades de indios y de españoles, constituyeron espacios liminales (ni ibéricos, ni indígenas), donde convergían todos los actores coloniales de la época. De esta forma, los miembros de las distintas castas durante la época colonial tuvieron una cercana interacción, que traía además consigo sus ideologías sobre el significado de sus cuerpos, sexualidad y comportamientos.

En general, los documentos legales, así como crónicas, relatan las circunstancias bajo las cuales los españoles abusaron de las mujeres andinas (Burkett 1990 [1978]; Mannarelli 1990). Estas descripciones sugieren que el abuso sexual ocurrió en modalidades y lugares distintos, en lugares como monasterios y los hogares españoles que estaban dentro de las ciudades españolas. Sin embargo, son los tambos los lugares mayormente mencionados en los documentos históricos donde se denunciaba la prostitución femenina. Al igual que en muchos otros espacios coloniales, los tambos se transformaron en lugares donde ocurrían violaciones sexuales, pero con la diferencia de que constantemente fueron denunciados como sitios en los que las mujeres indígenas se prostituían $^{15}$. Se observa que estas prácticas sexuales ocurrieron en modalidades distintas, ya sea porque los españoles utilizaron la fuerza o porque las mismas mujeres andinas se ofrecían a los españoles en retribución de dinero. En relación con ello, las ordenanzas de Vaca de Castro, y las más tardías dadas por el Marqués de Cañete en 1594, mencionan que parte de las responsabilidades que debían cumplir el encomendero o corregidor en los tambos era detener la prostitución de las mujeres indígenas. $\mathrm{Al}$ respecto, el padre Antonio de Ayans, interesado en denunciar las actividades en ellos, escribe «Hay algunos que vienen a los tambos y preguntan por mitayos para servirlos, lo primero que ellos hacen es ordenar a las jóvenes y atractivas mujeres indígenas con quienes ellos ofendían a Dios, y hay tantos que hacen lo mismo, que yo no mentiría si dijera que dos de cada tres personas hacen lo mismo [...] Otros toman ventaja de las esposas de los mitayos, los mandan ha hacer una u otra cosa, así tienen tiempo de tomar ventaja de sus mujeres» (Vargas Ugarte 1951 [1601-1718]: 53-56).

De la misma forma, en 1614, Guamán Poma describe y muestra el tipo de prácticas ocurridas en los tambos (Fig. 2). El cronista escribe: «Y demas de eso el dicho tanbero tiene media dozena de yndias putas de mal bevir y a otras yndias tiene con color de dezir mugeres de yanaconas [criados] o chinaconas [criadas] y algunas cazadas mugeres. Y destas se cirven y hazen grandes ofenzas del servicio de Dios y piden mitayas solteras y buidas o cazadas. Y alli se dańan, corrompen y se hazen grandes putas» (Guaman Poma de Ayala 1980 [1614]: 500-501). 


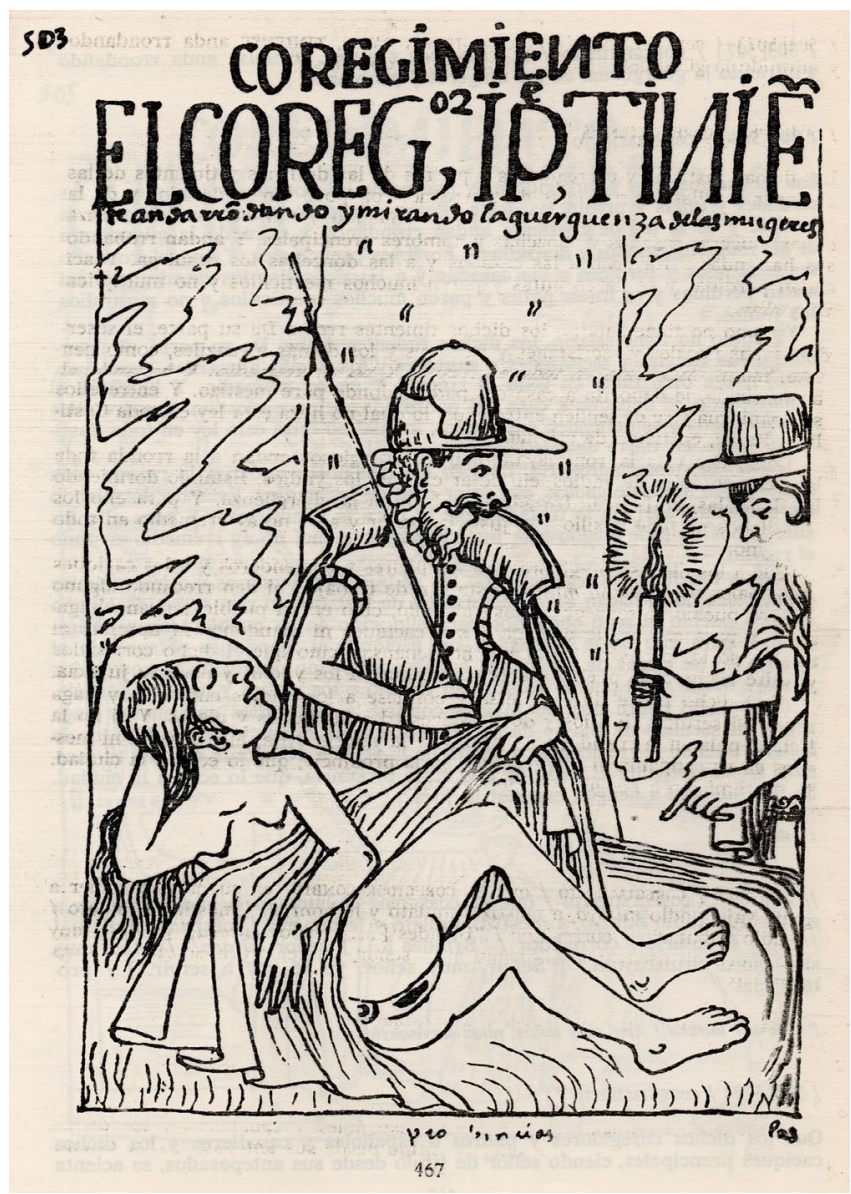

Figura 2. Figura que muestra las actividades licenciosas que ocurrian en los tambos según Guaman Poma de Ayala (1944 [1614]:f. 503).

No es raro, entonces, que las legislaciones de tambos intenten controlar las interacciones sociales de los actores que se encontraban en ellos, así como impedir estas prácticas. No obstante, queda preguntarse cuáles fueron las razones políticas y económicas tomadas por las mujeres indígenas para ejercer la prostitución en estos espacios.

A pesar de que es peligroso caer en especulaciones sobre la prostitución de las mujeres andinas y es un tema que puede resultar incómodo, la prostitución es tema recurrentemente mencionado en los tambos durante la Colonia. $\mathrm{Al}$ respecto, es ampliamente conocido cómo los y las indígenas luchaban para pagar los altos tributos impuestos por los españoles, y cómo en muchas ocasiones las comunidades andinas no llegaban a pagarlos. Bajo estas circunstancias, y como ha sido visto previamente, las mujeres andinas no fueron agentes pasivos e ingresaron a la economía colonial desde la marginalidad ${ }^{16}$. En este caso en particular, las mujeres utilizaban sus cuerpos y sexualidad en una economía colonial que lo permitía. De esta forma, se sugiere que los tambos, así como los mismos cuerpos de las mujeres indígenas, representaron un espacio de contestación ideológica y económica que merece futuras y serias investigaciones (Voss 2008).

De esta forma, las mujeres andinas vieron la prostitución — en los tambos-como una forma de sobrevivir durante el período colonial, o para ayudar a sus esposos, comunidades o a ellas mismas. Por ańos, los investigadores se han enfocado en la manera en que las mujeres andinas de élite se casaron con españoles o se convirtieron en sus concubinas como una manera de sobrevivir 
en la nueva sociedad colonial. De la misma forma, la prostitución como es hoy en día fue una forma de sobrevivir para las mujeres de bajos niveles sociales y fueron los tambos fueron los lugares que facilitaron estas actividades.

$\mathrm{Al}$ respecto, es interesante notar que, bajo contextos de colonización, la aparición de la prostitución indígena no es un tema que escapa de las relaciones de poder colonial. En primer lugar, a pesar de no haber encontrado referencia sobre prostíbulos en la Ciudad de los Reyes durante la época colonial temprana, sí existen para México. Estos fueron llevados a cabo principalmente por mujeres ibéricas o mestizas, pero no por indígenas. Probablemente, este escenario se relaciona con que el papel jugado por la mujer indígena dentro de la ciudad fue de sirvienta doméstica, lo cual suponía que las relaciones sexuales fueron parte de las relaciones de poder establecidas entre el jefe de familia y la servidumbre. En segundo lugar, el hecho de que los tambos sean nombrados como sitios donde la prostitución ocurrió recurrentemente es significativo. Se sugiere que la prostitución indígena femenina surge en los tambos, debido a que estos estuvieron fuera de las ciudades y porque fueron espacios comerciales donde coincidían todas las construcciones sociales coloniales que conformaban la sociedad.

Es importante indicar que para que exista prostitución indígena es necesario ser dueña o dueño del cuerpo, a la vez que exista una demanda ${ }^{17}$. Este último punto implica un deseo de los hombres (ibéricos, mestizos, negros, etc.) por los cuerpos indígenas femeninos y una oferta, es decir, la coyuntura de poder poner precio a un servicio prestado. Se sugiere que, dentro de todas estas transformaciones ideológicas coloniales, las mujeres indígenas pasaron por una intensa transformación sobre la percepción de su propio cuerpo, su sexualidad y el producto de los mismos (de sus hijos), lo que ha sido estudiado históricamente (Deagan 1973, 2001, 2004), pero que requiere de una intensa investigación arqueológica (Joyce 2008; Voss 2008).

Finalmente, se sugiere que el estudio de los tambos permite observar dos aspectos importantes. Uno es la preocupación colonial de controlar estos espacios como puntos de encuentro de los diferentes cuerpos (agentes) sociales que interactuaban entre ellos. El segundo es que, tras esta regulación y como consecuencia de la misma, se abrieron posibilidades de nuevos comportamientos entre las mujeres indígenas. Estas entraron a participar en la economía colonial haciendo uso de sus propios cuerpos y dentro de una nueva percepción de la sexualidad colonial (diferente a la prehispánica) que llevó a la comercialización del sexo ocurrida en los tambos.

\section{Discusión}

En los últimos años, la arqueología histórica en los Andes está dando grandes pasos. Muchos arqueólogos están interesados en observar espacios coloniales como doctrinas, reducciones e iglesias de la época transicional o colonial temprana (ver este número). Estos estudios están produciendo resultados interesantes e interpretaciones sobre los diferentes aspectos políticos y sociales de esta época. Siguiendo estos estudios, en este artículo, he presentado resultados de mis investigaciones y la manera en que veo la transformación de los tambos desde la época inca hasta la colonial temprana. De la misma forma, planteo una propuesta que llama la atención sobre los tambos coloniales y que permite un acercamiento de investigación desde múltiples perspectivas. $\mathrm{Al}$ mismo tiempo, sugiero que las investigaciones arqueológicas deben poner cuidado sobre utilizar ideas preconcebidas respecto a los tambos incas (o los prehispánicos) y su funcionamiento que vienen de la época colonial.

Respecto a los tambos incas, propongo que la idea que los tambos estuvieron sustentados o asociados a los pueblos directamente adyacentes es una relación que no es necesariamente válida. Estas instituciones no estaban a cargo de un pueblo indígena cercano, sino más bien de un ayllu (o guaranga) con poblaciones distribuidas en un espacio amplio que mitaban en varios tambos de la región. Al mismo tiempo, en el análisis de los tambos coloniales, se observa la existencia de una relación estrecha entre algunos grupos étnicos (ayllus) con tambos específicos. Se propone que esta última interacción (comunidad-tambo-imperio) sufrió transformaciones con la desaparición 


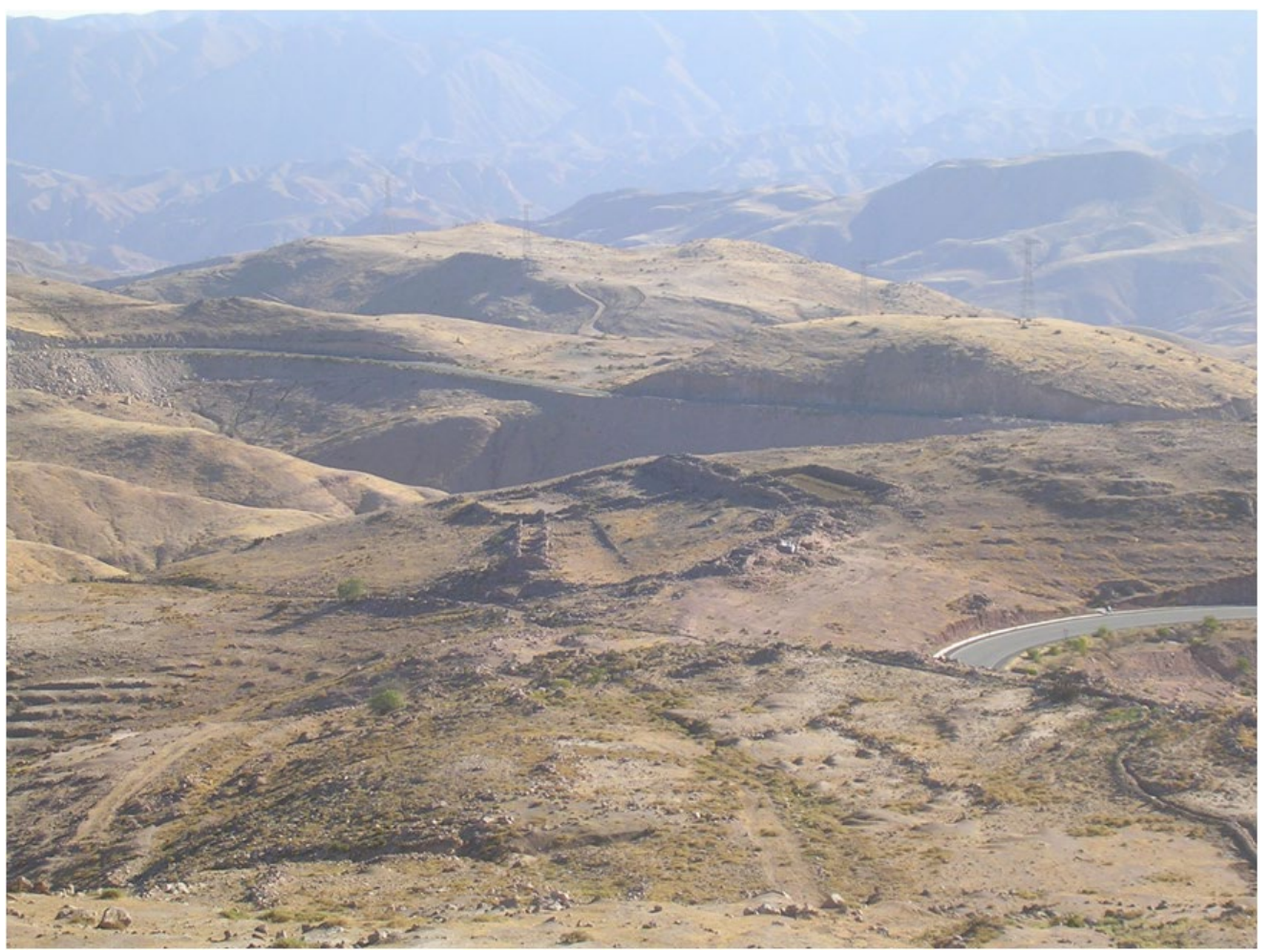

Figura 3. Vista Camata Tambo, Tambo Inca ubicado a 2,800 msnm en el valle alto de Moquegua, subregión del Colesuyo (Foto por S. Chacaltana).

del sistema imperial incaico, pero ocurrió dentro de un contexto que iba adquiriendo sentido en el nuevo discurso colonial ${ }^{18}$.

Por otro lado, en este trabajo, se critica el uso contemporáneo de la tipología de tambos de Guamán Poma de Ayala por parte de los investigadores andinos, tipología utilizada para clasificar a los tambos prehispánicos, y que responde más a una construcción colonial que una representación tipológica incaica. Asimismo, a pesar de que esta clasificación no sea relevante para entender los tambos durante la época prehispánica, sí lo es para acercarnos al proceso de transformación de los tambos durante la época colonial temprana. Esta tipología estuvo determinada por el número de mitayos requeridos en un tambo, venta o mesón. Los más ocupados estaban — por las leyes del mercado- ubicados en las ciudades o en caminos muy transitados. Otro aspecto que influyó en esta tipología fue la idea de que los tambos tenían que funcionar a manera de Guayna Capac (Vaca de Castro 1908 [1543]) o según costumbre (mencionado por Toledo en Lohmann Villena 1986 [1570-1574]: 74).

Entonces, los tambos representan una de las pocas instituciones prehispánicas que continuaron funcionando durante la época colonial. El tambo, como espacio, sobrevivió durante la época colonial temprana, pero las relaciones de poder relacionadas con este y la ideología alrededor del mismo se transformaron: adquirieron distintos significados y características. Es importante tomar en cuenta estas últimas al enfrentar un tambo tanto de manera histórica como al excavarlo. Los tambos cumplieron un rol importante para la función de la economía colonial y fueron instituciones que formaron parte de la contradictoria mentalidad colonial que lo sometieron a procesos regulatorios que tuvo sus propias características.

Con respecto a las investigaciones arqueológicas, hay algunas variables que podemos tomar en consideración, por ejemplo, la destrucción de los sistemas de almacenamiento localizados en 
los tambos durante la época colonial. Las qolqas ubicados en los tambos incas fueron las primeras estructuras que dejaron de funcionar durante los períodos coloniales (Lohman Villena 1986 [1570-1574]: 26-28). El sistema de almacenaje centralizado característico de los sitios incas funcionó bajo los principios prehispánicos de reciprocidad y redistribución, y era atendido a través de la mita otorgada al imperio por los miembros de ayllus cercanos. En cambio, durante el período colonial, los indígenas y los españoles podían ofrecer sus propios productos en venta. Es decir, el centralizado sistema de almacenamiento dejó de ser una función en los tambos. Esto debe tomarse en cuenta, así como se deben evaluar las variaciones locales y regionales que dependieron de los procesos históricos locales. Por ejemplo, a partir de las excavaciones llevadas a cabo por la autora en Camata Tambo, ubicado a 2800 metros sobre el nivel del mar, se observa que algunas qolqas cesaron de funcionar, pero otras contenían polen de trigo en su interior (Chacaltana 2010) (Fig. 3). A pesar de que este caso merece mayor atención, podría estar relacionado con que, durante la época colonial temprana, la zona del valle alto de Moquegua contó con una fuerte ocupación indígena local, que fue controlada por las élites lupacas del lago Titicaca (Cañedo-Arguelles 1993), en comparación con el valle medio, donde se encuentra la ciudad de Moquegua, que fue manejada por los españoles. Por ello, bajo este contexto, el uso de la tecnología prehispánica — como las qolqas - continuó por un tiempo entre los indígenas locales, procesos e hipótesis que deben ser tomados en consideración para entender contextos específicos.

\section{Conclusiones}

La perspectiva aquí tomada hacia los tambos coloniales sugiere que, a través del tiempo, las legislaciones de tambos fueron consecuencia de un diálogo constante (no fluido ni fácil) entre la idea reinventada de un tambo directamente relacionado con intereses coloniales. Asimismo, las legislaciones produjeron enfrentamientos, así como nuevas prácticas, que crearon una nueva institución. La ideología colonial vista a partir de las legislaciones de tambos y el edificio mismo constituyen un potencial arqueológico para estudiar la Colonia y las historias ocurridas en estos espacios, que son el reflejo de una compleja sociedad colonial y el encuentro de varios mundos, ideologías y prácticas.

\section{Notas}

${ }^{1}$ En la actualidad, existen discusiones sobre si fueron los tucuyricoc o los llactacamayocs los que administraron los tambos (Parsinnen 1992: 239; Cerrón Palomino 2006; Julien 2006). Se ha sugerido que estos oficiales fueron relocalizados por los incas desde regiones distantes de su lugar de origen, por lo que inmediatamente, luego del colapso imperial bajo conquista ibérica, algunos de estos oficiales retornaron a su lugar de origen.

${ }^{2}$ A pesar de que la crónica de Guamán Poma de Ayala no refiere a ordenanzas ni legislaciones de tambos, me detengo en ella con el objetivo de proponer que la tipología de tambos sugerida por el cronista fue consecuencia y materialización (ideológica) de un proceso de construcción de una categoría colonial, y no categorías prehispánicas como son tomadas en cuenta hoy en día por algunos arqueólogos.

${ }^{3}$ Existen otras ordenanzas que mencionan a los tambos, como, por ejemplo, las hechas en 1537 por Sebastián de Benalcazar, quien dispuso que los encomenderos podrían perder las encomiendas si no tenían poblados los tambos correspondientes a los caminos (ver Moreno Egas 2004: 100). También están las realizadas por Pedro de la Gasca en 1539, presidente del Virreinato de Lima, quien realizó una merced de tierra que denunciaban los abusos de los españoles a los indígenas en estos edificios, ya que no pagaban lo que consumían y además les arrebataban a sus mujeres (Glave 1989; Moreno Egas 2004: 101). En estas ordenanzas, se señalaba que era necesario que en los caminos reales se realicen y pueblen algunas ventas para que en ellas haya alojamiento y apro- 
visionamiento de tambos. Al parecer, fue durante el mando de la Gasca que se determinó tener un alguacil de tambo espańol.

${ }^{4}$ En general, desde muy temprano, existió una preocupación legislativa sobre la regulación del peso de la carga de los indígenas (Glave 1989); incluso, se reguló también para México.

${ }^{5}$ Estas disposiciones sobre los productos vendidos en los tambos tuvieron influencia regional; incluso, se implementaron en Quito, lo cual afectó a los tambos, así como a las interacciones locales (ver Moreno Egas 2004: 101).

${ }^{6}$ Esto es interesante, porque, en 1570 , por disposición de Francisco de Toledo, estos perdieron la capacidad de designar a los mitayos de tambos.

${ }^{7}$ Esta será una actividad que también será vista por Francisco de Toledo en 1570 (más adelante).

${ }^{8}$ Ello también fue comentado por Rostworowski (1987-1989), quien notó que no solo los pueblos adyacentes eran los que cumplían la mita de tambos en estas instituciones. Al respecto, esta característica parece ser una constante en los Andes, debido a que en la Visita de Huánuco podemos ver que había indígenas que servían en tambos alejados de su pueblo de origen, aun habiendo tambos más cercanos.

${ }^{9}$ La guaranga de Guacapongo, guaranga de Llucho, guaranga de Llampa, guaranga de mitimaes serranos, guaranga de mitimaes yungas, y guaranga chaupi yungas.

${ }^{10}$ Una guaranga refiere a un grupo étnico cuyos pobladores estaban distribuidos en un territorio. Por ello, en esta ordenanza, se pueden ver miembros de guarangas que están ubicados en distintas comunidades.

${ }^{11}$ Como lo mencionara Rostworowski (1987-1989), sería interesante realizar un proyecto de investigación arqueológica en esta región para poder observar la relación entre la distancia de los tambos y las guarangas (y sus respectivos pueblos) nombradas por la visita, así como la diferencia de espacios, y tipos de actividades o porcentaje de cerámica imperial y local en los mismos. Estos estudios tendrían la potencialidad de identificar patrones de actividades, que también reflejarían variaciones y similitudes entre los tambos.

${ }^{12}$ Esto también se evidencia en las ordenanzas de Vaca de Castro (1908 [1543]) y en los pleitos presentados más adelante en este artículo. Se dispone que los indios dejen de cumplir mita de tambo en pueblos lejanos, lo cual generó conflictos entre los pueblos locales.

${ }^{13}$ Chucuito, en realidad, fue el sitio administrativo Lupaca durante la época inca y que continuó siendo utilizado durante la época colonial (Julien 1982).

${ }^{14}$ Los corregidores de indios fueron las autoridades encargadas de supervisar la administración indígena en los pueblos de indios y respecto a sus asuntos.

${ }^{15}$ Es decir, ofrecían un servicio sexual a cambio de una paga económica.

${ }^{16}$ En este caso, se hace hincapié en que, a pesar de que estas prácticas permitieron a las mujeres indígenas acceder a ganar dinero, esto ocurrió dentro de una estructura de poder en la que las mujeres eran subyugadas y parte de una ideología que no solo las consideraba por debajo de la naturaleza masculina, sino también peligrosas.

${ }^{17}$ Demanda producto de un deseo y una oferta. Al respecto, la atracción de los cuerpos de los colonizadores hacia las mujeres de zonas conquistadas ha sido anteriormente estudiada (Ballantyne y Burton 2005). Por otro lado, el deseo implica aspectos ideológicos sobre la construcción de los comportamientos sexuales del otro, pero, específicamente, la prostitución también depende de la oferta, es decir, de la posibilidad de poner precio a un servicio, puesto que, al no ser libres las mujeres indígenas (negras, mulatas, etc.) en las ciudades, no podían hacerlo. 
${ }^{18}$ Esto se ve repetidamente en varios tipos de documentos como en la Visita de Huánuco (Ortiz de Zuñiga 1967 [1562]), así como en las dos disputas de tambos presentadas más adelante. En este caso, sugiero que estas prácticas prehispánicas se fueron transformando durante la época colonial, y fueron provocadas y manipuladas por los indígenas que tomaban provecho de las leyes coloniales para construir su propia historia y tener mejores beneficios.

\section{REFERENCIAS}

\section{Ballantyne, T. y A. Burton}

2005 Introduction: Bodies, empires, and world histories, en: T. Ballantyne y A. Burton (eds.), Bodies in contact. Rethinking colonial encounters in world history, 1-15, Duke University Press, Durham. https://doi.

Bárcena, R. org/10.1215/9780822386452-001

1988 Investigación de la dominación incaica de Mendoza. El tambo de tambillos, la vialidad anexa y los altos

Barriga, $\mathbf{V}$. cerros cercanos, Espacio, Tiempo y Forma, Serie I, Pre-historia 1, 397-426.

1939 Documentos para la historia de Arequipa (1534-1558), Tomo I, Editorial La Colmena, Arequipa.

Betanzos, J. D. de

2004 Suma y narración de los Incas (seguida del Discurso sobre la descendencia y gobierno de los Incas)

[1557] (edición de María del Carmen Martín Rubio), Ediciones Polifemo, Madrid.

Botmiliau, A. de

1947 La República peruana. La sociedad peruana, en: R. Porras Barnechea (ed.), Viajeros del Perú, 131-216,

[1848] Editorial Cultura Antartica S.A., Lima.

Burkett, E.

1990 Las mujeres indígenas y la sociedad blanca: El caso del Perú del siglo XVI, en: A. Lavrin (ed.), Las

[1978] mujeres latinoamericanas: Perspectivas históricas, 121-152, Fondo de Cultura Económica, México D.F.

Cañedo-Arguelles, T.

1993 La organización del poder indígena en el Colesuyo (siglo XVI), Revista Complutense de Historia de América 19, 21-51.

2005 La visita de Juan Gutiérrez Flores al Colesuyo y pleitos por los cacicazgos de Torata y Moquegua, Fondo Editorial de la Pontificia Universidad Católica del Perú, Lima.

Cardona, A.

2008 Caminos prehispánicos de Arequipa (edición de Cerro Verde), Centro de Investigaciones, Arequipa.

Cerrón Palomino, R.

2006 Tucuyricoc, Boletín de la Academia Peruana de la Lengua 42, 209-226.

Chacaltana Cortez, $S$.

2010 El rol de los sistemas de almacenamiento de Camata Tambo y Camata Pueblo, un tambo inca y una comunidad local adyacente ubicados en la región del Colesuyo, Valle Alto de Moquegua (en publicación), tesis de Licenciatura, Facultad de Letras y Ciencias Humanas, Pontificia Universidad Católica del Perú, Lima.

2011 Evidencias arqueológicas en Camata Tambo, tambo inca ubicado en el valle alto de Moquegua, Andes sur-centrales, Arqueología y Sociedad 21- Edición especial (Homenaje a Craig Morris).

deCerteau, $M$.

1999 La invención de lo cotidiano. II Habitar, cocinar, Universidad Iberoamericana, México D.F.

Deagan, K.

1973 Mestizaje in colonial St. Agustine, Ethnohistory 20 (1), 55-65. https://doi.org/10.2307/481426

2001 Dynamics of Imperial Adjustment in Spanish America: Ideology and Social Integration, en: S.E. Alcock, T.N. D’Altroy, K.D. Morrison y C.M. Sinopoli (eds.), Empires. Perspectives from archaeology and history, 179-194, Cambridge University Press, Cambridge.

2004 Reconsidering Taíno social dynamics after Spanish conquest: Gender and class in culture contact studies, American Antiquity 69 (4), 597-626. https://doi.org/10.2307/4128440 
deViera, A. de la compañía de Jesús

1734 Todos sus sermones y obras diferentes que de su original portugues se han traducido al español. Reducidos esta privera vez a orden e impresos en quatro tomos, Edición de Juan Pieferrer, Barcelona.

Diez de San Miguel, G.

1964 Visita hecha a la provincia de Chucuito por Garci Diez de San Miguel, Documentos Regionales para la

[1567] Etnohistoria Andina 1, Lima.

Espinoza Soriano, W.

1997 Virreinato peruano. Vida cotidiana, instituciones y cultura, Biblioteca Nacional del Perú, Lima.

2005 Las lenguas nativas del altiplano peruano-boliviano en el siglo XVI. Investigaciones Sociales 14, 121-153.

Esstenssoro, J. C.

2010 Autorretrato del conquistador como vencido o la invención del Perú: La aparición del inca y de sus atributos políticos en las representaciones plásticas, 1526-1548, Colonial Latin American Review 19 (1), 151-205. https://doi.org/10.1080/10609161003643727

Flores, C. y C. Revilla

2006 Ocupación inka en la región Kallawaya: Oralidad, etnohistoria y arqueología de Camata, Bolivia, Chungara 38 (2), 223-238. https://doi.org/10.4067/s0717-73562006000200006

Glave, L. M.

1989 Trajinantes. Caminos indígenas en la sociedad colonial. Siglos XVI/XVII, Instituto de Apoyo Agrario, Lima.

Guamán Poma de Ayala, F.

1944 Primer nueva corónica y buen gobierno (edición de ing. Arthur Posnansky), Editorial del Instituto

[1614] Tihuanacu de Antropología, Etnografía y Prehistoria, La Paz.

Guevara Gil, A. y F. Salomon

2004 "A Personal Visit»: Colonial political ritual and the making of Indians in the Andes, Colonial Latin American Review 3 (1-2), 3-36. https://doi.org/10.1080/10609169408569822

Helsley, A.

1980 Excavations at Cerro Tambo Real Lambayeque, Peru, tesis inédita de bachillerato, Departamento de Antropología, Princeton University, New Jersey.

Hyslop, J.

1984 The Inka road, Academic Press, New York.

1990 Inka settlement planning, University of Texas Press, Austin.

Instituto Nacional de Cultura

2004 Proyecto Qhapaq Nan, informe de campaña 2002-2004, Instituto Nacional de Cultura, Lima.

Joyce, R.

2008 Ancient bodies, ancient lives. Sex, gender, and archaeology, Thames and Hudson, New York.

Julien, C.

1982 Inca decimal administration in the Lake Titicaca Region, en: G. Collier, R. Rosaldo y J. Wirth (eds.), The Inka and the Aztecs, 129-133, Academic Press, New York.

2006 An Inca information network, Nawpa Pacha 28, 41-61. https://doi.org/10.1179/naw.2006.28.1.004

2007 Francisco de Toledo and his campaign against the Incas, Colonial Latin American Review 16 (2), 243272.

Kauffman-Doig, F.

2001 Sexo en el antiguo Perú, Quebecor World Perú, Lima.

Levillier, R.

1925 Gobernantes del Perú: Cartas y papeles. Siglo XVI. Documentos del Archivo de Indias, vol. VIII, Imprenta de Juan Pueyo, Madrid.

Lockhart, J.

1994 Spanish Peru, 1532-1560: A social history, The University of Wisconsin Press, Madison.

Lohman Villena, G.

1986 Francisco de Toledo. Disposiciones gubernativas para el virreinato del Perú 1569-1574, Tomo I, Escuela de Estudios Hispano-Americanos, Sevilla.

1989 Francisco de Toledo. Disposiciones gubernativas para el virreinato del Perú 1574-1580, Tomo II, Escuela de Estudios Hispano-Americanos, Sevilla. 
Lopez-Baralt, $\mathrm{M}$.

2003 Comentarios reales: La florida del Inca. Garcilaso de la Vega, 1539-1616, Espasa Calpa, Madrid.

Mannarelli, M. E.

1990 Sexualidad y desigualdades genéricas en el Perú del Siglo XVI, Allpanchis 22 (35-36), 225-248.

1993 Pecados públicos. La ilegitimidad en Lima, siglo XVII, Ediciones Flora Tristán, Lima.

1998 Espacios femeninos en la sociedad colonial, en: C. Meza y T. Hampe (eds.), La mujer en la historia del Perú (siglos XV al XX), 191-215, Biblioteca del Congreso del Perú, Lima.

Matienzo, J. de

1910 Gobierno del Perú con todas las cosas pertenecientes a él y a su historia, 1567, Universidad Nacional

[1567] Facultad de Filosofía y Letras, Buenos Aires.

\section{Moreno Egas, J.}

2004 Los tambos de la jurisdicción de Quito en el siglo XV, en: J. Núnez Sánchez (ed.), Memoria Social Histórica en el Ecuador, Memorias de VII Congreso Nacional de Historia y Geografía de la Casa de la Cultura Económica «Benjamín Carrión», 97-111, Sección Académica de Histórica y Geografía, Quito.

Morris, C.

1967 Storage in Tawantinsuyo, tesis de doctorado, Departamento de Antropología, University of Chicago, Chicago.

1986 Storage, supply and redistribution in the economy of the Inka state, en: J. Murra, N. Watchel y J. Revel (eds.), Anthropological history of Andean polities, 59-68, Cambridge University Press, Cambridge. https://doi.org/10.1017/cbo9780511753091.009

1992 Huanuco Pampa and Tunsukancha: Major and minor nodes in the Inka storage network, en: T. LeVine (ed.), Inka storage systems, 151-175, University of Oklahoma Press, Norman/London.

Morris, C. y A. Covey

2003 La plaza central de Huánuco Pampa: Espacio y transformación, Boletín de Arqueología PUCP 7 , 133-149.

Mumford, J. R.

2007 Litigation as ethnography in sixteenth-century Perú: Polo de Ondegardo and the mitimaes, Hispanic American Historical Review 88, 1-40.

Murra, John

1980 The economic organization of the Inka state, Jai Press Inc., Greenwich.

Ortiz de Zúñiga, I.

1967 Visita de la provincia de León de Huánuco en 1562, Facultad de Letras y Educación, Huánuco.

[1562]

Parssinen, $M$.

1992 Tawantinsuyu. The Incas state in its political organization, The Finnish Historical Society, Helsinski.

Pizarro, P.

1969 Relación de los descubrimientos y conquista de los reinos del Perú, vol. I, The Cortes Society, New York. [1571]

Poma de Ayala, G.

1944 Primer nueva corónica y buen gobierno (edición de A. Posnansky), Editorial del Instituto

[1614] Tihuanacu de Antropología, Etnografía y Prehistoria, La Paz.

\section{Rostworowski de Diez Canseco, M.}

1975 Algunos comentarios hechos a las ordenanzas del doctor Cuenca, Historia y Cultura 9, 119-154.

1987- Ordenanzas para el servicio de los tambos del repartimiento de Huamachuco hecho por el licenciado

1989 Gonzales de Cuenca en 1567, Revista Histórica 36, 15-31.

Salomon, F.

1998 Collquiri's dam: The colonial re-voicing of an appeal to the archaic, en: E. Boonne y T. Cummins (eds.), Native traditions in the postconquest world, 265-293, Dumbarton Oaks, Washington D.C.

Silverblatt, I.

1987 Moon, Sun, and witches. Gender ideologies and class in Inca and colonial Peru, Princeton University Press, New Jersey. 


\section{Socolow, S. M.}

2000 The women of colonial Latin American, Cambridge University Press, Cambridge. https://doi.org/10.1017/ СBO9780511840074

\section{Tschauner, $\mathrm{H}$.}

2001 Socioeconomic and political organization in the Late Prehispanic Lambayeque sphere, northern coast of Peru, tesis de doctorado, Harvard University, Cambridge.

Vaca de Castro, C.

1908 Ordenanzas de tambos. Distancia de unos a otros, modo de cargar los indios y obligaciones de las

[1543] justicias respectivas hechas en la ciudad del Cuzco, Revista Histórica, tomo III (4).

\section{Vargas Ugarte, R.}

1951 Pareceres juridicos en asuntos de Indias (1601-1718), CIP, Lima.

\section{Viera Powers, K.}

2005 Women in the crucible of conquest:The gendered genesis of Spanish American society, 1500-1600, University of New Mexico Press, Albuquerque.

Voss, B.

2008 Sexuality studies in archaeology, The Annual Review of Anthropology37,317-336. https://doi.org/10.1146/ annurev.anthro.37.081407.085238

Xeres, F. de

1872 Itinerary of Francisco Pizarro in the account of Xeres, en: C. R. Markham (ed.), Report on the discovery [1534] of Peru, 3-71, Burt Franklin, New York.

Zárate, A.

1995 Historia del descubrimiento y conquista del Perú, Colecciones Clásicos Peruanos PUCP, Lima.

[1555] 